\title{
First Report of Black Spot Caused by Alternaria alternata on Grafted Cactus
}

\author{
Min-Ok Choi ${ }^{1}$, Sang Gyu Kim¹, Ik-Hwa Hyun ${ }^{2}$, Jeong Ho Kim ${ }^{3}$, Chang-Hui Cho ${ }^{4}$, Myung Soo Park ${ }^{5}$ and \\ Young Ho Kim ${ }^{1 *}$ \\ ${ }^{1}$ Department of Agricultural Biotechnology, Seoul National University, Seoul 191-521, Korea \\ ${ }^{2}$ National Plant Quarantine Service, Anyang 430-016, Korea \\ ${ }^{3}$ Korea Turfgrass Institute, Subsidiary of Korea Golf Course Business Association, Sungnam 463-840, Korea \\ ${ }^{4}$ Cactus Research Institute, Gyeonggi-do Agricultural Experimental Station, Goyang 411-809, Korea \\ ${ }^{5}$ Chemical Biotechnology Research Center, KRICT, Daejeon 305-605, Korea
}

(Received on June 25, 2009; Accepted on November 25, 2009)

\begin{abstract}
A stem spot disease was observed on Gymnocalycium mihanovichii (Korean name: Bimoran), a scion of graftcactus, in major growing areas of Goyang and Eumseong, Korea during 2008 and 2009. Typical symptoms were initial blackish brown lesions produced mainly on areoles and scars of injured stem tissues, gradually becoming large black spots. A causal organism isolate CD2-7A isolated from the infected stems was identified as Alternaria alternata based on its morphological characteristics and confirmed by the DNA sequencing analysis of ITS, glyceraldehydes-3-phosphate dehydrogenase (gpd), and allergen Alt a1 (Alt a 1) genes. Artificial inoculation of the fungal isolate CD2-7A produced the same rot symptoms on the cactus stems, from which the same fungus was isolated and identified. This is the first report of the black spot caused by $A$. alternata in the grafted cactus.
\end{abstract}

Keywords : Alternaria alternata, graft-cactus, Gymnocalycium mihanovichii, pathogenicity

Most cactuses are stem succulents, having fleshy stems. A grafted cactus, which is composed of stock and scion cactuses, is a major commercial product in Korea and one of the most important exporting ornamental plants due to its high quality in the world market. The most widely cultivated stock cactus is a three-angled cactus (Hylocereus trigonus), while two scion cactuses commonly used in Korea are Gymnocalycium mihanovichii and Chamaecereus silvestrii, of which the Korean common names are Bimoran and Sanchui, respectively. G. mihanovichii is more popularly cultivated in Korea than $C$. silvestrii.

One of the limiting factors for cultivating grafted cactuses in greenhouses is due to stem rot diseases especially caused by fungi. They include stem rots caused by Fusarium oxysporum (Chang et al., 1998), Bipolaris cactivora (Hyun

\footnotetext{
*Corresponding author.

Phone) +82-2-880-4675, FAX) +82-2-873-2317

E-mail)yhokim@snu.ac.kr
}

et al., 1998; Kim et al., 2004), and Glomerella cingulata (Kim et al., 2000). In our surveys of cactus diseases during 2008 and 2009, however, we often observed some stem diseases of $G$. mihanovichii with no fungi belonging to the above reported genera.

Therefore, we report the occurrence of a fungal stem disease of $G$ mihanovichii and the identification and characterization of the fungal pathogen.

Disease occurrence and symptoms. Occurrence of a stem disease was observed frequently on G. Mihanovichii in major growing areas of Goyang and Eumseong, Korea during 2008 and 2009. Symptoms were characterized by blackish brown lesions produced mainly on areoles and scars of injured stem tissues (Fig. 1A, B). Sometimes large portions of the cactus stems were diseased with large black spots at advanced infection stages.

Fungal isolation and pathogenicity. Pathogen isolation was conducted using infected G. mihanovichii stems. Small stem tissues were cut from the edge of the diseased area with flame-sterilized razor blade and surface-sterilized with $75 \%$ ethanol for $30 \mathrm{sec}$ and $1 \%$ sodium hypochlorite for 60 $\mathrm{sec}$, and rinsed with sterile water. The stem tissues were placed on potato-dextrose agar (PDA) supplemented with $0.1 \%$ lactic acid, incubating at $25^{\circ} \mathrm{C}$ for 3-4 days in an incubator. Fungal mycelia grown from the stem tissues were transferred to fresh PDA, incubating at $25^{\circ} \mathrm{C}$ for 7 days. We selected several isolates producing dictyosporic conidia typical of genus Alternaria, of which isolate CD27A was used as a type culture for further studies.

For pathogenicity test, the fungal isolate was grown on $10 \%$ V-8 juice agar $(10 \%(\mathrm{v} / \mathrm{v}) \mathrm{V}-8$ juice, $0.3 \%(\mathrm{w} / \mathrm{v})$ $\mathrm{CaCO}_{3}$ and 2.0\% Bacto-agar in $1000 \mathrm{ml}$ distilled water) at $25^{\circ} \mathrm{C}$ for 2 weeks, from which spores were collected in sterile distilled water (SDW) by scratching the fungal culture surfaces and filtered through two layers of cheesecloth to make spore suspension. The spore suspension was centrifuged at $6,370 \times \mathrm{G}$ for $10 \mathrm{~min}$ and re-suspended and diluted 

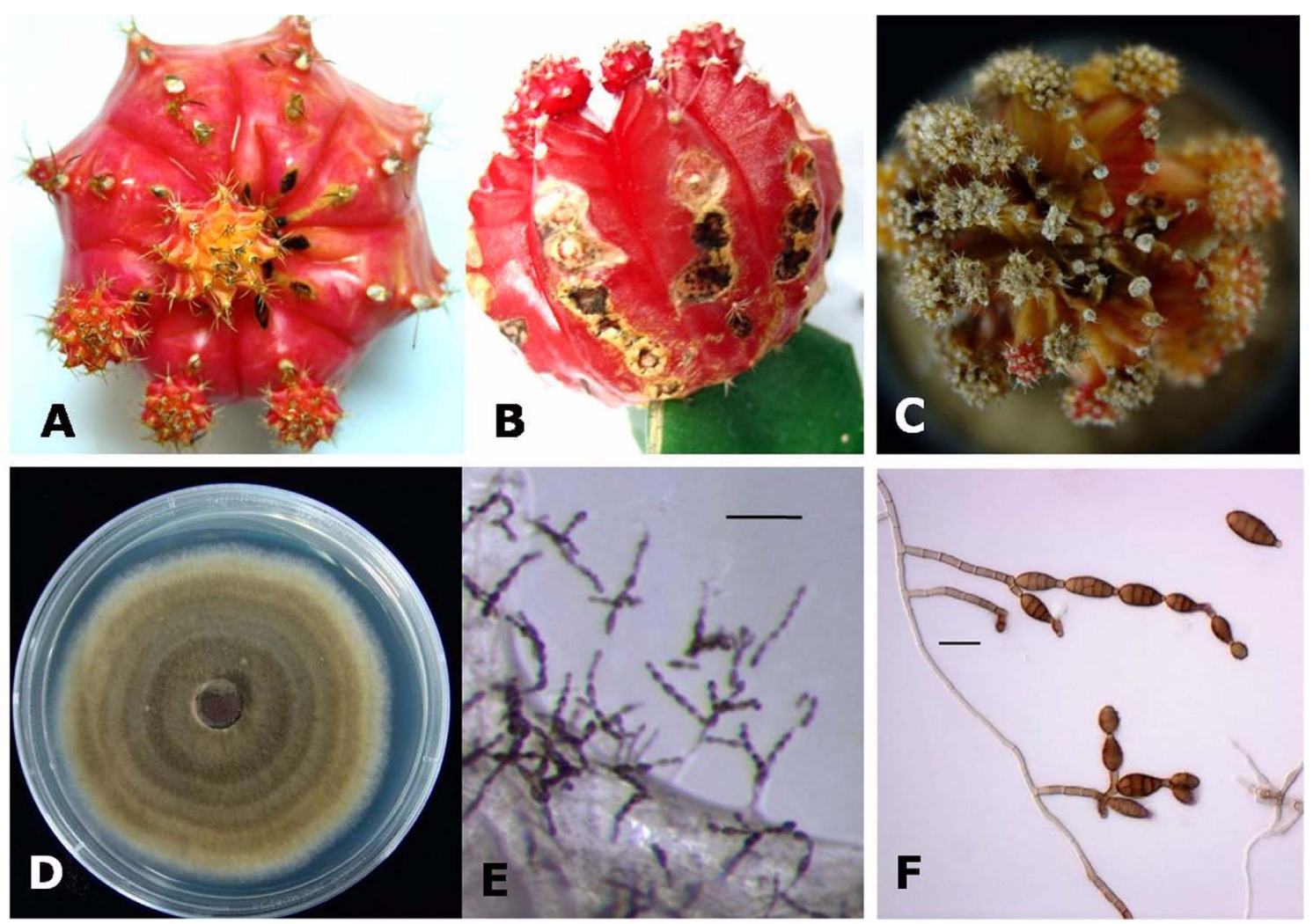

Fig. 1. Symptoms of black spots on Gymnocalycium mihanovichii naturally infected (A, B) and artificially induced at 10 days after inoculation (C), fungal colony produced on potato-dextrose agar (D) and light microscopic pictures of fungal spores (E, F). Bars represent $100 \mu \mathrm{m}$ and $20 \mu \mathrm{m}$ for $\mathrm{E}$ and $\mathrm{F}$, respectively.

in SDW to make a concentration of ca. $5 \times 10^{5}$ spores $/ \mathrm{ml}$. For inoculation, one-year-old stems of $G$. mihanovichii were inoculated with the fungus by dropping $0.01 \mathrm{ml}$ of the spore suspension on a wound of ca. $0.5 \mathrm{~mm}$ (diameter) $\times 5 \mathrm{~mm}$ (depth) made with a syringe needle, and placed at $25^{\circ} \mathrm{C}$ and $\mathrm{RH} 40 \%$ in a growth chamber after placing them under saturated humid conditions for one day. The experiment replicated three times and SDW was used as control.

The fungal isolate caused initial symptoms of brownish lesions on the inoculation sites of the cactus stem at 3 days after inoculation, and the lesions were blackened and enlarged with time, comprising a large diseased area at a late infection stage (Fig. 1C). The same fungus was reisolated from the diseased area. Water-inoculated control did not induce any rot symptoms (data not shown).

Table 1. Comparison of morphological characteristics of the present isolate CD2-7A with Alternaria alternata reported previously

\begin{tabular}{lllll}
\hline \hline & Characteristics & & \multicolumn{1}{c}{ CD2-7A } & \multicolumn{1}{c}{ Ellis $^{\mathrm{a}}$} \\
\cline { 3 - 5 } & Color & $\begin{array}{l}\text { Velvety, olivaceous brown } \\
\text { to black }\end{array}$ & $\begin{array}{l}\text { Olivaceous black to sooty } \\
\text { black }\end{array}$ & $\begin{array}{l}\text { Velvety, olivaceous black to } \\
\text { sooty black }\end{array}$ \\
\hline Conidiophores & Shape & $\begin{array}{l}\text { Solitary or in small fascicles } \\
\text { Up to } 60\end{array}$ & $\begin{array}{l}\text { Solitary or in small fascicles } \\
\text { Up to } 50\end{array}$ & $\begin{array}{l}\text { Solitary or in small fascicles } \\
\text { Up to } 80\end{array}$ \\
& Length $(\mu \mathrm{m})$ & $3.0-4.5$ & $3.0-6.0$ & $3.0-5.0$ \\
\hline Conidia & Width $(\mu \mathrm{m})$ & Ellipsoid to ovoid, obclavate & $\begin{array}{l}\text { Ellipsoid to ovoid, obclavate to Ellipsoid to ovoid, obclavate to } \\
\text { obpyriform }\end{array}$ \\
& Shape & & $20 \sim 63 \times 9 \sim 18$ & $13 \sim 35(43) \times 8 \sim 14$ \\
& Size $(\mu \mathrm{m})$ & $10 \sim 37(60) \times 6 \sim 12$ & $3 \sim 5$ transverse & $3 \sim 5$ transverse \\
& Septa & $(2) 3 \sim 4(6)$ transverse & $1(2)$ longitudinal & $1(2)$ longitudinal \\
\hline
\end{tabular}

${ }^{\mathrm{a}}$ Described by Ellis (1977); ${ }^{\mathrm{b}}$ Described by Yu (2001) 
Identification of the fungal isolate. The fungal isolate CD2-7A formed velvety, olivaceous brown or olive-green to sooty black colonies with partly superficial mycelium on PDA (Fig. 1D). Light microscopic observations showed branched hyphae, hyaline at first but later pale brown to brown; conidiophores solitary or in small fascicles, commonly branched, pale brown, up to $60 \mu \mathrm{m}$ long, 3-4.5 $\mu \mathrm{m}$ wide; conidia commonly in moderately long or long chains of 3-10, branched or not, pale brown to brown, mostly ellipsoid to ovoid, conidium body 10 37 (60) $\times 6 \sim 12 \mu \mathrm{m}$ with (2) 3 4 (6) transverse septa and 1 2 (4) longitudinal septa (Fig. 1E, F). These morphological characters of the present isolate coincide with those of Alternaria alternata described by Ellis (1971) and Yu (2001) (Table 1).

Genomic DNAs of CD2-7A were used for sequencing of ITS, glyceraldehydes-3-phosphate dehydrogenase (gpd) gene and Alt a1 gene. Using the primers, ITS 1 (TCCGTAGGTGAACCTGCGG) and ITS 4 (TCCTCCGCTTATTGATATGC) for ITS, gpd 1 (CAACGGCTTCGGTCGCATTG) and gpd 2 (GCCAAGCAGTTGGTTGTGC) for gpd gene, and Alt-for (ATGCAGTTCACAACCATCGC) and Alt-rev (ACGAGGGTGAYGTAGGCGTC) for Alt a 1 gene, these genes were amplified by PCR following the processes previously described by White et al. (1990), Berbee et al. (1999), and Hong et al. (2005), respectively. Amplified DNA fragments were subjected to electrophoresis in 1.0\% agarose gel, and the target DNA bands were purified and sequenced on an Applied Biosystems DNA Sequencer (model ABI 3700). The resulting sequences were compared to the GenBank database using the NCBI BLAST search program. A total of 955 base sequences determined from the ITS DNA were $100 \%$ identical to those of several $A$. alternata strains with NCBI accession nos. EJ946480.1, AB4708380.1, AB470832.1 and AB470831.1. A total of 1020 base sequences from gpd gene were $100 \%$ identical to A. alternata with no. EF513205.1. Also a total of 743 base sequences from Alt a 1 gene were identical to those of several A. alternata strains or isolates with nos. U86752.1, U82633.1 and AF288160.1. Thus, based on the results, the fungal isolate CD2-7A was confirmed to be A. alternata.

The fungal pathogen isolated from the stem rot of $G$. mihanovichii was identified as A. alternata. In pathogenicity test, this fungus formed lesions on the cactus stem rapidly, although severe diseases were not frequently found in natural greenhouse conditions. This suggests that it has a possibility to outbreak in some environmental conditions favorable for the disease development. A variety of crops other than the cactus are infected with A. alternata, including safflower (leaf spot) (Park and Lee, 2003), kiwifruit (brown ring spot on leaves) (Jeong et al., 2008), and sweet persimmon (black spot) (Kwon et al., 2004). However, this is the first report that Alternaria alternata is a causal pathogen of the stem disease of the grafted cactus. We here propose to name this disease as black spot of G. mihanovichii because of its typical symptom appearance of a black lesion.

\section{Acknowledgement}

This Study was supported by Technology Development Program for Agriculture and Forestry, Ministry for Agriculture, Forestry and Fisheries, Republic of Korea.

\section{References}

Berbee, M. L., Pirseyedi, M. and Hubbard, S. 1999. Cochliobolus phylogenetics and the origin of known, highly virulent pathogens, inferred from ITS and glyceraldehydes-3-phosphate dehydrogenase gene sequences. Mycologia 91:964-977.

Chang M., Hyun, I. H. and Lee, Y. H. 1988. Bipolaris stem rot of cactus caused by Bipolaris cactivora (Petrak) Alcorn. Korean J. Plant Pathol. 14:661-663.

Ellis, M. B. 1977. Dematiaceous Hyphomycetes. Common wealth Mycological Institute. Kew, Surrey, England. 608 pp.

Hong, S. G., Cramer, R. A., Lawrence, C. G. and Pryor, B. M. 2005. Alt a 1 allergen homologs from Alternaria and related taxa: analysis of phylogenetic content and secondary structure. Fungal Genet. Biol. 42:119-129.

Hyun, I. H., Lee, S. D., Lee, Y. H. and Heo, N. Y. 1988. Mycological characteristics and pathogenicity of Fusarium oxysporum Schlecht. Emend. Snyd. \& Hans. causing stem rot of cactus. Korean J. Plant Pathol. 14:463-466.

Jeong, I. H., Kim, G. H., Lim, M. T., Hur, J.-S., Shin, J. S. and Koh, Y. J. 2008. Brown ring spot on leaves of kiwifruit caused by Alternaria alternata. Res. Plant Dis. 14:68-70.

Kim, J. H., Jeoung, M.-I., Hyun, I.-H. and Kim, Y. H. 2004. Potential biotypes in Korean isolates of Bipolaris cactivora associated with stem rot of cactus. Plant Pathol. J. 20:165-171.

Kim, Y. H., Jun, O. K., Sung, M. J., Shin, J.-S., Kim, J. H. and Jeoung M.-I. 2000. Occurrence of Colletotrichum stem rot caused by Glomerella cingulata on graft-cactus in Korea. Plant Pathol. J. 16:242-245.

Kwon, J.- H., Ahn, G.-H. and Park, C.-S. 2004. Black spot of sweet persimmon (Diospyros kaki) caused by Alternaria alternata. Res. Plant Dis. 10:183-187.

Park, K. S. and Lee, S. G. 2003. Leaf spot of safflower (Carthamus thinctorius) caused by Alternaria carthami and A. alternata. Res. Plant Dis. 9:159-161.

White, T. J., Bruns, T., Lee, S. and Taylor, J. 1990. Amplification and direct sequencing of fungal ribosomal RNA genes for phylogenetics. In: PCR Protocols: A Guide to Methods and Application eds. by M. A. Innis, D. H. Gelfand, J. J. Sninsky and J. J. White, pp. 315-322. Academic Press, New York, USA.

Yu, S. H. 2001. Korean Species of Alternaria and Stemphylium. National Institute of Agricultural Science and Technology, Suwon, Korea 212 pp. 